\title{
A Study of Mental Health Status of College Going Youths of Kashmir
}

\author{
Rizwan Hassan Bhat ${ }^{1}$, Jahangeer Majeed ${ }^{2}$
}

\section{ABSTRACT:}

This study was conducted to evaluate the mental health status among youths. Descriptive survey Method was used in this study to obtain pertinent and precise information. The hypotheses of the study were to know the relationship between mental health status and emotional stability, overall-adjustment, autonomy, self concept, security-insecurity and intelligence of youths, to find out the difference in mental health status of youth boys and girls, to find out the difference in emotional stability, overall-adjustment, autonomy, self concept, security-insecurity and intelligence. The sample of this study included 300 youths selected by stratified random sampling from the district Baramulla Kashmir. The one standardized tool was used by the investigator to evaluate the mental health status of youths in relation to their emotional stability, overall-adjustment, autonomy, self concept, security-insecurity and intelligence. In order to draw out the results the investigator used statistical techniques like t'tests, mean and standard deviation with graphical representations. The conclusions of the study are that there exists no significant difference between Mental health status and emotional stability, Mental health status and overall-adjustment, Mental health status and autonomy, Mental health status and self concept, Mental health status and security-insecurity, Mental health status and intelligence of youth boys and girls.

Keywords: Mental Health, College Going-Youths, Kashmir, self-concept, Overall-adjustment, autonomy, security-insecurity, intelligence and emotional stability.

Mental health is not just the absence of mental illness. It is defined as a state of Well-being in which every individual realizes his or her own potential, can cope with the normal stresses of life, can work productively and fruitfully, and is able to make a contribution to his or her community.

Mental health is defined as the capacity to feel, think and act in ways that enhance one's ability to enjoy life and deal with challenges. Expressed differently, mental health refers to various capacities including the ability to: understand oneself and one's life; relate to other people and respond to one's environment,

${ }^{1}$ Department of psychology, Aligarh Muslim University Aligarh (U.P)
${ }^{2}$ Department of psychology, Aligarh Muslim University Aligarh (U.P)

(C) 2015 I R Bhat, J Majeed; licensee IJIP. This is an Open Access Research distributed under the terms of the Creative Commons Attribution License (http://creativecommons.org/licenses/by/2.0), which permits unrestricted use, distribution, and reproduction in any Medium, provided the original work is properly cited. 


\section{A Study of Mental Health Status of College Going Youths of Kashmir}

experience pleasure and enjoyment; handle stress and withstand discomfort; evaluate challenges and problems; pursue goals and interests; and explore choices and make decisions

Mental health is vital for individuals, families and communities, and is more than simply the absence of a mental disorder. Mental health is defined by the World Health Organization (WHO) as 'a state of well-being in which the individual realizes his or her own abilities, can cope with the normal stresses of life, can work productively and fruitfully, and is able to make a contribution to his or her community.

\section{DIMENSIONS OF MENTAL HEALTH:}

- INTELLIGENCE.

- OVER ALL-ADJUSTMENT.

- EMOTIONAL STABILITY.

- AUTONOMY.

- SELF CONCEPT.

- SECURITY AND INSECURITY.

\section{OBJECTIVES OF THE STUDY:-}

There are number of studies conducted in India and abroad on mental health status but present study focuses on the following main objectives: - The purpose of present study was to examine the dimensions of mental health status viz., emotional stability (ES), over-all adjustment (OA), autonomy (AY), security-in security (AY), self concept (SI), and intelligence (IG) in college going boys and girls of Kashmir.

\section{HYPOTHESIS:}

1. There would be a significant difference between boys and girls on emotional stability dimension of mental health status.

2. There would be a significant difference between boys and girls on overall adjustment dimension of mental health status.

3. There would be a significant difference between boys and girls on autonomy dimension of mental health status

4. There would be a significant difference between boys and girls on self-concept dimension of mental health status.

5. There would be a significant difference between boys and girls on security-insecurity dimension of mental health status.

6. There would be a significant difference between boys and girls on intelligence dimension of mental health status 


\section{A Study of Mental Health Status of College Going Youths of Kashmir}

\section{METHODOLOGY:}

This study includes first to select the sampling group to carry out the study. In this case, sample includes a group of youths of the age of 20-23 years. The study will then include the selection of the appropriate methods like scales to access the variables to be measured. Following the assessment of the variables, a right statistical approach is taken to authenticate the results for their significance.

Sampling:-The sample of the present study consisted of 300 students with equal number of boys and girls (150 boys and 150 girls) from three different colleges. The youth sample was selected from BA/B.SC I, II and III classes. All the sample units $(\mathrm{N}=300)$ were drawn from various colleges located in Baramulla district of Kashmir.

Sample was collected from the following colleges of Baramulla district of Kashmir.

Table1

Showing the names of the schools

\begin{tabular}{|l|l|l|l|}
\hline Sr. No & Name of schools & No. of girls & No. of boys \\
\hline 1 & $\begin{array}{l}\text { Govt. Degree College } \\
\text { Baramulla }\end{array}$ & 50 & 50 \\
\hline 2 & $\begin{array}{l}\text { Govt. Degree College } \\
\text { Sopore }\end{array}$ & 50 & 50 \\
\hline 3 & Govt. College Pattan & 50 & 50 \\
\hline
\end{tabular}

Both groups of youths (Age range 18-23) were matched in terms of their age, economic status and inhabitation.

\section{Tests and Materials:}

Mental Health Battery (MHB) was used in this study.

\section{Mental Health Battery (MHB):-}

In order to ascertain the level of mental health status among subjects, English version of Mental Health Battery developed by Singh and Sen Gupta (1987) was used in the present study. Mental Health Battery intends to assess the mental health status of persons in the age range of 18-23 years, as it is a battery of six (6) tests, the mental health battery consists of 130 items which are divided into six (6) parts. 
Dimension wise distribution of items for mental health battery.

\begin{tabular}{|l|l|}
\hline Part I: Emotional Stability (ES) & 15 \\
\hline Part II: Overall Adjustment (OA) & 40 \\
\hline Part III: Autonomy (AY) & 15 \\
\hline Part IV: Security Insecurity (SI) & 15 \\
\hline Part V: Self-Concept (SC) & 15 \\
\hline Part VI: Intelligence (IG) & 30 \\
\hline Total & 130 \\
\hline
\end{tabular}

In the battery there is no fixed time limit for first five (5) parts. However, generally in normal subject having average mental health takes about 25 minutes in giving complete answers. Part six (6) is a speed test. The total allotted time for this part is ten minutes.

1: Analysis On the basis of Emotional Stability: Emotional stability refers to the state of being able to have the appropriate feelings about the common experiences and being able to act in a rational manner. Emotional stability is not only one of the effective determinants of the personality patterns, but it also helps to control the growth of adolescent development. The concept of stable emotional behavior at any level is that which reflects the fruits of the normal emotional development. An individual who is able to keep his emotions stable and under control even in extreme situations, might still be emotionally stunned or be childish in his behavior sometimes. Therefore emotional stability is considered as one of the important aspect of human life. People must be able to control their emotions adequately and also express them appropriately. Below given table indicates that there does not exist any significant difference between the two groups on emotional stability.

Table.1 Comparison of two groups on Emotional Stability

\begin{tabular}{|l|l|l|l|l|l|l|}
\hline Variable & Group & N & Mean & SD & t & P \\
\hline $\begin{array}{l}\text { Emotional } \\
\text { Stability }\end{array}$ & Boys & $\mathbf{1 5 0}$ & 8.32 & 1.926 & .274 & NS \\
\hline & Girls & $\mathbf{1 5 0}$ & 8.26 & 1.862 & & \\
\hline
\end{tabular}




\section{A Study of Mental Health Status of College Going Youths of Kashmir}

A perusal of table 1 reveals that mean emotional stability scores of youth boys and girls were 8.32 and 8.26, with SD 1.926 and 1.862 respectively. The t-ratio between the means of the two groups was found to be .274 which was not significant at 0.01 level of significance.

Ciarrochi et al. suggested that emotional indicators and stressor factors impacted on sociopsychological health status. Salovey, that EI was associated with mental health, and individuals with higher EI were able to deal better with stress and were less vulnerable in stress.

2. Analysis On the basis of Overall adjustment: Adjustment is a built - in mechanism for coping with the problematic or other realities of life. Adjustment has been considered as an index to integration; a harmonious behavior of the individual by which other individual of society recognize person is well adjusted. (Pathak, 1990). Below drawn table shows that on overall adjustment there does not exist any significant difference between two groups.

Table.2 Comparison of two groups on Overall adjustment

\begin{tabular}{|l|l|l|l|l|l|l|}
\hline Variable & Group & N & Mean & SD & t & P \\
\hline $\begin{array}{l}\text { Overall } \\
\text { adjustment }\end{array}$ & Boys & $\mathbf{1 5 0}$ & 25.33 & 4.261 & .246 & NS \\
\hline & Girls & $\mathbf{1 5 0}$ & 25.21 & 4.186 & & \\
\hline
\end{tabular}

A look at table 2 reveals that mean overall adjustment scores of youth boys and girls were 25.33 and 25.21, with SD 4.261 and 4.186 respectively. The t-value between the means of the two groups was found to be .246 which was not significant at .01 level of significance.

Menninger (1945) defined mental health as the adjustment of human beings to the world and to each other with a maximum of effectiveness and happiness.

Anand (1999) conducted a study on mental health of 370 students of IX, X, XI and XII grades. He reported no significant impact of gender and class on the mental health.

3. Analysis On the basis of Autonomy; Autonomy is an individual's capacity for selfdetermination or governance. Autonomy is generally held in high esteem. It serves as one of the central concepts in many philosophical debates, e.g. on understanding ourselves as persons, on how to conceptualize morality, on the legitimization of political norms and practices as well as on questions in bio-medical ethics. The table does not show any significant difference between two groups on Autonomy. 
Table: 3 Comparison of two groups on Autonomy

\begin{tabular}{|l|l|l|l|l|l|l|}
\hline Variable & Group & N & Mean & SD & t & P \\
\hline Autonomy & Boys & 150 & 7.59 & 1.589 & .432 & NS \\
\hline & Girls & 150 & 7.51 & 1.617 & & \\
\hline
\end{tabular}

Table 3 depicts that the mean Autonomy scores of youth boys and girls were 7.59 and 7.51, with SD 1.589 and 1.617 respectively. The t-value between the means of the two groups was found to be .432 which was not significant at .01 level of significance.

Autonomy has been identified as an intrinsic psychological need that, when realized, promotes mental health and well-being. The failure to develop autonomy, it has been hypothesized, may lead to decreased motivation and lowered self-esteem (Ryan \& Deci, 2000).

Autonomy represents a cornerstone of psychological theories of personality development (Mahler, Pine, \& Bergman, 1975) maintained that the development of an autonomous and psychological healthy person resulted from the process of separation and individuation.

4 Analysis on the basis of Self-Concept; Self-concept is the way people think about themselves. It is unique, dynamic, and always evolving. This mental image of oneself influences a person's identity, self-esteem, body image, and role in society. As a global understanding of one's self, self-concept shapes and defines who we are, the decisions we make, and the relationships. Self- concept is perhaps the basis for all motivated behavior. Table is the indicator that there is no significant difference on self-concept between the two groups.

Table: 4 Comparison of two groups on Self-Concept

\begin{tabular}{|l|l|l|l|l|l|l|}
\hline Variable & Group & N & Mean & SD & t & P \\
\hline $\begin{array}{l}\text { Self- } \\
\text { Concept }\end{array}$ & Boys & $\mathbf{1 5 0}$ & 7.71 & 1.256 & .369 & NS \\
\hline & Girls & $\mathbf{1 5 0}$ & $\mathbf{7 . 6 5}$ & 1.248 & & \\
\hline
\end{tabular}

A perusal of table 4 reveals that mean self-concept scores of youth boys and girls were 7.71and 7.65, with SD 1.256 and 1.248 respectively. The t-ratio between the means of the two groups was found to be .369 which was not significant at 0.01 level of confidence. Self-concept is the sum of an individual's beliefs and knowledge about his personal attributes and qualities, it is a cognitive schema that organizes abstract and concrete views about the self, and controls the processing of self-relevant information Markus, 1977; Kihlstrom and Cantor, 1993 Selfconcept is considered as equivalent to self-regard, self-estimation and self-worth (Harter, 1999). Sartorius (Sartorius, 1998), the former WHO Director of Mental Health, preferred to define it as a means by which individuals, groups or large populations can enhance their competence, selfconcept and sense of well-being. 


\section{A Study of Mental Health Status of College Going Youths of Kashmir}

According to Tudor (Tudor, 1996), self-concept, identity and self-esteem are among the key elements of mental health. Again (1996) in his monograph on mental health promotion, where he presents self-concept and self-esteem as two of the core elements of mental health, and therefore as an important focus of mental health promotion.

\section{Analysis on the basis of Security-Insecurity Security:}

In contexts of poor security, public health interventions and the delivery of health care to the individual are more difficult to perform and less likely to succeed than in contexts of security. Violence - including the threat of violence - in such contexts results in injury, death, psychological harm, impaired development or deprivation.

\section{Insecurity:}

Insecurity, therefore, potentially has a double impact on people's lives and well-being; this is the reality of everyday life for many millions of people. The nexus of security, insecurity and health is as complex as it is important. In a given context, responsibility for what happens at this nexus falls to multiple actors, including ministries responsible for health, defense and internal affairs; the overriding influence, especially on security, may even be the foreign policy of other countries. On security-insecurity table does not indicate any significant difference between the two groups.

Table: 5 Comparison of two groups on Security-Insecurity

\begin{tabular}{|l|l|l|l|l|l|l|}
\hline Variable & Group & $\boldsymbol{N}$ & Mean & SD & $\boldsymbol{t}$ & $\boldsymbol{P}$ \\
\hline $\begin{array}{l}\text { Security- } \\
\text { Insecurity }\end{array}$ & Boys & $\mathbf{1 5 0}$ & 7.63 & 1.662 & .471 & NS \\
\hline & Girls & $\mathbf{1 5 0}$ & 7.54 & 1.536 & & \\
\hline
\end{tabular}

Table 5 depicts that the mean security-Insecurity scores of youth boys and girls were 7.63 and 7.54, with SD 1.662 and 1.536 respectively. The t-value between the means of the two groups was found to be .471 which was not significant at .01 level of significance. Young people development is due to love and affection and sense of security which is further dependent on the attitude of parents towards their children (Bossard \& Boll, 1954). The insecurity state of a person is an emotional problem, a state of being in disturbance due to the feeling of tension, strain and conflict together with other consequences of tension.

According to Shankar, (1958) emotional security prepares the ground for mental health and creative activities of the individuals by which they make adjustments to their environment. 


\section{A Study of Mental Health Status of College Going Youths of Kashmir}

\section{Analysis on the basis of Intelligence}

A very general mental capability that, among other things, involves the ability to reason, plan, solve problems, think abstractly, comprehend complex ideas, learn quickly and learn from experience. It is not merely book learning, a narrow academic skill, or test-taking smarts. Rather, it reflects a broader and deeper capability for comprehending our surroundings-"catching on," "making sense" of things, or "figuring out" what to do. Intelligence has been defined in many different ways such as in terms of one's capacity for logic, abstract thought, understanding, selfawareness, communication, learning, emotional knowledge, Memory, planning, and problem solving. Below given table proves that there is no significant difference between two groups on intelligence.

Table: 6 Comparison of two groups on Intelligence

\begin{tabular}{|l|l|l|l|l|l|l|}
\hline Variable & Group & N & Mean & SD & t & P \\
\hline Intelligence & Boys & $\mathbf{1 5 0}$ & 17.85 & 3.772 & .595 & NS \\
\hline & Girls & $\mathbf{1 5 0}$ & 17.59 & 3.630 & & \\
& & & & & & \\
\hline
\end{tabular}

A look at table. 6 reveals that mean Intelligence scores of youth boys and girls were 17.85 and 17.59, with SD 3.772 and 3.630 respectively. The t-value between the means of the two groups was found to be .595 which was not significant at .01 level of significance.Goleman (1995) suggested the need to bring intelligence to emotions. Goleman tells us that we really have two different ways of understanding, intellectually and emotionally and our mental life results from the interaction of both functions. It means mental health directly depends on head and heart because intellectual development depends on head (brain) and emotional development depends on heart.

\section{CONCLUSIONS}

Results of the study show the acceptance or rejection of the hypotheses. Conclusions of study are:

1. There exists no significant difference between boys and girls on emotional stability dimension of mental health.

2. There exists no significant difference between boys and girls on overall adjustment dimension of mental health.

3. There exists no significant difference between boys and girls on autonomy dimension of mental health.

4. There exists no significant difference between boys and girls on self-concept dimension of mental health.

5. There exists no significant difference between boys and girls on security-insecurity dimension of mental health.

6. There exists no significant difference between boys and girls on intelligence dimension of mental health. 


\section{A Study of Mental Health Status of College Going Youths of Kashmir}

\section{SUGGESTIONS:}

1. The Study can be conducted on college going and university level students.

2. The study can be conducted by considering the High and Low mental health.

3. The Mental health of teachers can be evaluated too.

4. Other variables like Anxiety, self- efficacy, emotional intelligence, academic motivation and other constructs can also be included for further research.

\section{. REFERENCES}

1. Angermeyer, M., B. Schulze, et al. (2003). "Courtesy stigma: A focus group study Of relatives of schizophrenia patients." Social Psychiatry and Psychiatric

Epidemiology 38: 593-602.

2. Ahmad, N., B., S., Bae, S., Meador, K. E., Huang, R., \& Singh, K. P. (2009). Association between obesity and asthma in US children and adolescents.

3. Aleen and Sheema. (2005). Emotional stability among college youth. J. IndAcademAppl Psycho! 31:99-1 02.

4. Alka M. Mankad (1999). Personality Measurement or Emotionality Matured Adolescent Youth and Emotionally Immature People, 5th International-and 36th Indian "Academy of Applied. Psychology Conference, Souvenir. December 27, 297\&30

5. Bell, L. M., Byrne, S., Thompson, A., Ratnam, N., Blair, E., \& Bulsara, M., et al. (2007). Increasing body mass index z-score is continuously associated with complications of overweight in children, even in the healthy weight range. The Journal of Clinical Endocrinology and Metabolism, 92(2), 517-522. doi:10.1210/jc.2006-1714.

6. Blubberbusters. (2010, November 8, 2010), from Bruce M, McAvay G, Raue P, Brown E, Meyers B, Keohane D, Jagoda D, Weber C. Major Depression in elderly home health care patients. American Journal of Psychiatry.2002; 159:1367-1374

7. Banks, M. (2003). "Disability in the family life: A life span perspective."Cultural Diversity and Ethnic Minority Psychology 9(4): 367-384.

8. B.C Minister of Health's Advisory Council on Mental Health (2002)

9. Babyak ,M.Blumenthal, J.A.Herman, S.Khatri, P.Doraiswamy, M.,Moore, K.Craighead, E.Baldwicz, T.T. and Krishnan. R.(2000). Psychosomatic Medicine, vol.62 (5), pp.633-638.

10. Burrows A.B., Morris J.N., Simon S.E., Hirdes J.P., and Phillips C. Development of a minimum Data Set-based depression rating scale for use in nursing homes. Age and Aging. 2000; 29:165-172.

11. Bandura, A. (1989). Perceived self-efficacy in the exercise of personal agency. The Psychologist: Bulletin of the British Psychological Society, 2,411-424.

12. Brussen, Kerri Anne (2010). Youth Mental Health. Chisholm Health Ethics 


\section{A Study of Mental Health Status of College Going Youths of Kashmir}

Bulletin, Vol. 16, No. 1, Spring 2010: 1-4.Cokes, C \& Kornblum, W 2010, Journal of Black Studies, vol. 34, no. 1, pp. 24-35.

13. Cairney J, Krause N.(2005). The social distribution of psychological distress and Depression in older adults. Journal of Aging and Health. 2005;17:807-835

14. Caria, M. P., Bellocco, R., Zambon, A., Horton, N. J., \& Galanti, M. R. (2009). Addiction, 104(4), 661-668.

15.Fernando S., (1995); Mental Health in a Multi.Ethnic Society: a Multi-disciplinary Hadbook, Routledge, UK.

16. Fakhri, M.K., Banihashemian, K., 2012. Correlation between General Health with Emotional Intelligence and Creativity in Medical College Students at Islamic Azad University, Sari Branch, Sari, Iran, Qom University of Medical Sciences Journal, Vol. 6, No 2.

17.Goleman, D., (1995). Emotional intelligence: Why it can matter more than IQ. New

York: Bantam. Lane, R., \& McRae, K., (2004). Neural substrates of conscious Emotional experience, $87-122$.

18. Garrett, H. E. (1981). Statistics in psychology and education. Bombay: Vaklis, Feffer and Simons Pvt. Ltd. 